\title{
KNOWLEDGE, ATTITUDE AND PRACTICES REGARDING BREAST FEEDING, A PICTURE IN EAST KHASI HILLS DISTRICT OF MEGHALAYA.
}

Star Pala, Himashree Bhattacharyya, Apurba Marak, Bhanu Pratap Singh, Neilatu- U-Suokhrie

1. Assistant Professor, Department of Community Medicine, NEIGRIHMS, Shillong, Meghalaya.

2. Senior Resident Doctor, Department of Community Medicine, NEIGRIHMS, Shillong, Meghalaya.

3. Senior Resident Doctor, Department of Community Medicine, NEIGRIHMS, Shillong, Meghalaya.

4. Senior Resident Doctor, Department of Community Medicine, NEIGRIHMS, Shillong, Meghalaya.

5. Lady Medical Officer, Department of Community Medicine, NEIGRIHMS, Shillong, Meghalaya.

\section{CORRESPONDING AUTHOR}

Dr. Himashree Bhattacharyya,

Dept. of Community Medicine,

NEIGRIHMS, Mawdiangdiang,

Shillong- 793018, Meghalaya.

E-mail: bhimashre@yahoo.co.in

Ph: 0091 94369-85886

ABSTRACT: INTRODUCTION: Breast feeding is the normal way of providing young infants with the nutrients they need for healthy growth and development. A child who is breast fed has greater chances of survival than a child who is artificially fed. The low prevalence and duration of exclusive and partial breastfeeding increase the risk of infant and childhood morbidity and mortality in both developed and developing countries. Worldwide, suboptimal breastfeeding still accounts for deaths of 1.4 million children aged less than five years . AIM OF THE STUDY: 1. To assess the knowledge, attitude and practices regarding breast feeding among women 2 . To study the factors influencing breast feeding practices among women residing in East Khasi Hills district of Meghalaya. METHODOLOGY: The present study is a cross sectional study conducted within the field practice area of NEIGRIHMS, two of which were urban- Nongmynsong and Pynthorbah and one rural area-Tynring. The study period was conducted from October 2012December 2012 (three months duration). A total of 135 women were interviewed during the period. In the respective areas the households were selected using simple random sampling after obtaining a list of all the households in the respective area from the ANM. In the selected household all the females available who have a child between 1-2 year of age were interviewed. Data analysis was done by descriptive analysis and analytical statistics by using Chi Square test using SPSS version 17.0. RESULTS \& OBSERVATION: Out of 135 families visited, 70 (51.9\%) families were nuclear families. With respect to feeding practices; 80 (59\%) mothers had given Exclusive Breast Feeding for a period of 6 months. 74 (55\%) of mothers had knowledge on colostrums and 109 (80.75\%) of mothers had given colostrum to their babies. 42 (31.1\%) mothers had initiated BF within 1 hour .The variables which were found to be associated with breast feeding are the mother's age, type of family and the mother's education. CONCLUSION: Mothers education was found to be an important factor in influencing breast feeding practices. Therefore, Health education and counseling of mothers can go a long way in improving breast feeding practices in this area.

KEY WORDS: Breast feeding, Infant, Knowledge, Attitude, Practices.

INTRODUCTION: Breast feeding is the normal way of providing young infants with the nutrients they need for healthy growth and development. Breast milk has just the right amount 
of fat, sugar, water, and protein that is needed for a baby's growth and development. ${ }^{1}$ Childhood under-nutrition in our country mostly originates from inadequate and faulty practices of feeding newborns and children, coupled with exposure to contaminated environment. The low prevalence and duration of exclusive and partial breastfeeding increase the risk of infant and childhood morbidity and mortality in both developed and developing countries. ${ }^{2}$ Worldwide, suboptimal breastfeeding still accounts for deaths of 1.4 million children aged less than five years .The timely introduction of complementary feeding can prevent almost $6 \%$ of under-five mortality. ${ }^{3}$

In India, Breastfeeding is almost universal, but the Exclusive Breast Feeding rate is quite low. Third National Family Health Survey (NFHS III) from India reports Exclusive Breast Feeding rates of $46.3 \%$ at 5 months ${ }^{4}$. Though various factors are there which can influence the practice of breast feeding, lack of adequate knowledge can be considered as one of the vital factors. With this background the present study was conducted to assess the knowledge, attitude and practices regarding breast feeding and factors influencing breast feeding practices among women residing in East Khasi Hills district of Meghalaya.

MATERIALS AND METHODOLOGY: The present study is a cross sectional study conducted within the field practice area of NEIGRIHMS, two of which were urban- Nongmynsong and Pynthorbah and one rural area-Tynring. The study period was conducted from October 2012 to December 2012 (three months duration). Considering the prevalence of Exclusive Breast Feeding as $46.4 \%$ in India (as per NFHS III data) ${ }^{4}$ and taking $20 \%$ as allowable error, the sample size was calculated to be 115 . In our study period, however a total of 135 women were interviewed. In the respective areas, the household was selected as the sampling unit. The number of individuals selected from each area was determined by proportionate allocation depending on the total population of the area. In the respective areas the households were selected using simple random sampling after obtaining a list of all the households in the respective area from the ANM. In the selected household all the females available who have a child between 1-2 year of age were interviewed. Data was collected on socio demographic characteristics of the women, breast feeding practices and knowledge on breast feeding. The tool used to collect data was a pre tested questionnaire. The respondents were informed about the purpose of the study. They were assured about confidentiality. Questions were asked in local vernacular language. A p value of $<.05$ was considered as significant. Data analysis was done by descriptive analysis and analytical statistics by using Chi Square test using SPSS version 17.0.

RESULTS AND OBSERVATIONS: A total of 135 women were interviewed for the study. Out of 135 families visited, 70 (51.9\%) families were nuclear families .With respect to fathers age 16 (11.9\%) fathers belonged to $<25$ years of age; most of the fathers $109(80.7 \%)$ belonged to 25 45 years and 7 (5.2\%) belonged to $>45$ years. Data for 3 fathers could not be taken as they had expired. Regarding father's education 21 (15.6\%) were found to be illiterate and $111(82.2 \%)$ were literate. With respect to the father's income, 2(1.5\%) had income < 1000, $60(44.4 \%)$ had income between 1001-5000, 43 (31.9\%) had income of Rs 5001-10000; 18 (13.3\%) had income $10000-20000$ and 5 (3.7\%) had income $>20000$. Data for 7 fathers could not be collected as 3 had expired and 4 fathers were not working. With respect to mother's age 40 (28.1\%) belonged to $\leq 25$ years of age, 77 (57.03\%) belonged to age group 26-35 years and 18 (13.33\%) belonged to $36-45$ years of age. Data gathered for mothers education revealed that $40(29.6 \%)$ were 
illiterate and 95(70.4\%) were literate. With respect to mothers occupation, $116(85.9 \%)$ were housewives and the rest 19 (14.1\%) were working women. 116 (85.9\%) delivered in institutions and $19(14.1 \%)$ delivered at home. 19 (14.1\%) babies had birth weight $<2.5 \mathrm{~kg}$ and $99(73.3 \%)$ had birth weight $\geq 2.5 \mathrm{~kg}$. For 17 babies birth weight could not be found out as they were delivered at home.

With respect to feeding practices; 80 (59\%) mothers had given Exclusive Breast Feeding for a period of 6 months. It was found that 74 (55\%) of mothers had knowledge on colostrum. $109(80.75 \%)$ mothers were found to give colostrum to their babies. 42 (31.1\%) mothers had initiated BF within 1 hour, 38 (28.14\%) had initiated within 1-12 hours; 30 (22.22\%) had initiated within 12-24 hours and 25 (18.51\%) had initiated BF beyond 24 hours. 28 (21.75\%) mothers had given pre lacteal feeds, $107(78.25 \%)$ had not given. With respect to artificial feeding, 55 (41\%) had given artificial feeding to their babies. In our study only $35(25.9 \%)$ of babies were weaned correctly at 6 months. 86 (63.7\%) mothers commented that BF helps in growth of baby and 49 (36.29\%) gave other reasons like to fill the stomach, satisfy the hunger, protects from infections etc.

In our study, a significant relation was observed between the mother's age and Exclusive Breast feeding with the younger mothers more likely to breast feed than the elderly mothers.( Chi $\mathrm{Sq}=8.546, \mathrm{df}=2, \mathrm{p}=0.0139$ ). In our study, we found a significant association between the type of family and Exclusive breast feeding with mothers belonging to non nuclear families more likely to breast feed ( $\mathrm{Chi} \mathrm{Sq}=12.244, \mathrm{df}=1, \mathrm{p}=0.0005$ ). No relation was observed between mother's occupation and Exclusive breast feeding. (Chi $S q=0.7852, d f=1, p=0.3755$ ). A significant relation was observed between mother's education and Exclusive Breast Feeding. (Chi $\mathrm{Sq}=9.903, \mathrm{df}=1, \mathrm{p}=0.0016$ ). A significant relation was also observed between mother's education and knowledge on colostrum. (Chi $\mathrm{Sq}=25.855, \mathrm{df}=1, \mathrm{p}<0.0001$ ) and also giving of colostrums to their babies (Chi $\mathrm{Sq}=31.791, \mathrm{df}=1, \mathrm{p}<0.0001$ ). No significant relation was observed between time of initiation of Breast feeding and place of delivery. (Chi Sq=1.662, $\mathrm{df}=1, \mathrm{p}=0.197$ ). We also found no significant relation between pre lacteal feeding and place of delivery (Chi Sq=.000, $\mathrm{df}=1, \mathrm{p}=0.985$ ). No significant relation was observed between mothers education and pre lacteal feeding ( $\mathrm{Chi} \mathrm{Sq}=0.0189, \mathrm{df}=1, \mathrm{p}=0.8904$ ). Also no significant relation was observed between fathers education and $\mathrm{EBF}$ (Chi Sq=2.373, $\mathrm{df}=2, \mathrm{p}=0.305$ ).

DISCUSSION: In our study around $80(59.3 \%)$ were found to give Exclusive Breast feeding to their babies. In a study conducted in Bankura district of West Bengal, exclusive breastfeeding under six months was found to be $57.1 \%$ which is similar to the present study ${ }^{5}$ but slightly higher than the NFHS III figure of $46.4 \%$ 4. We observed that 109 (80.75\%) of mothers had given colostrum to their babies. In a study conducted in Nepal on knowledge, attitude and practices regarding colostrums, $80 \%$ of mothers were found to give colostrums to their babies which is similar to the present study ${ }^{6}$. In our study, we found that $42(31.11 \%)$ had initiated breast feeding within 1 hour. In a study conducted in Bankura district of West it was found that only $13.6 \%$ of the study children were put to the breast within one hour of birth ${ }^{5}$. In a study on breast feeding practices of rural and urban mothers conducted in New Delhi it was observed that only $21 \%$ urban and 35\% rural mothers initiated breastfeeding within one hour of birth which is somewhat similar to the present study ${ }^{7}$. It was found from our study that $28(21.75 \%)$ mothers had given pre lacteal feeds. In a study on infant feeding practices in Nagpur, India it was found that $47(21.65 \%)$ mothers used pre lacteal feeds which are similar to the present study ${ }^{8}$. In another study conducted in Bankura, West Bengal the overall prevalence of prelacteal 
feeding was $26.7 \%$. In the present study we observed that only $35(25.9 \%)$ of mothers had introduced complementary feeding at the correct time i.e by 6 months. Panwar et al in his study found that $19.3 \%$ of infants were weaned at the correct age of 6 months ${ }^{9}$. The figure reported by UNICEF is found to be $29.6 \%$ which is almost similar to the present study ${ }^{10}$.

The factors which were found to be significantly associated with Exclusive Breast feeding are the mother's age, type of family and mothers education. In a study on maternal knowledge and perception about the breast feeding and factors influencing it conducted in Pune it was found that factors like illiteracy and living in nuclear family were associated with higher risk of not giving EBF ${ }^{11}$. In another study conducted by Rajesk K Sudasama et al in South Gujrat region of India showed socio demographic variables like maternal education, type of family has significant_association with the new borns_exclusive breast feeding but no association was found with maternal age ${ }^{12}$. In our study we did not find any association between Exclusive breast feeding and mothers occupation. The reason may be that the number of working mothers in the study were too less in our study to find any significant association. Also, no significant association was observed between time of initiation of Breast feeding and place of delivery. This is because the numbers of home deliveries are less in the present study to find any significant association. Also the type of delivery and the condition of mother, attitude of health care provider and family members are more important factors in predicting early initiation of breast feeding rather than place of delivery alone. We had observed a significant association between mother's education level and knowledge on colostrums including giving of colostrums to their babies. In a study conducted by Sunil Kumar Joshi et al conducted in Nepal, educated women were found to have higher knowledge on colostrums and maternal education remained important with regard to awareness about the importance of colostrum feeding ${ }^{6}$. No significant association was however observed between mother's education level and pre lacteal feeding. This may be due to the reason that it is mainly the relatives like in laws who take care of the baby immediately after the delivery and mothers are usually confined to bed and have little say at that timed.

CONCLUSION: In our study the Exclusive Breast feeding up to 6 months was found to be higher than other areas which is encouraging. The problems that were found in our study were late initiation of breast feeding, introduction of pre lacteal feeding and faulty complementary feeding. Mother's education was found to be an important factor in influencing breast feeding practices. Therefore, Health education and counseling of mothers can go a long way in improving breast feeding practices in this area.

\section{REFRENCES:}

1. World Health Organization; Health Topics- Breast feeding. Available at http:// www.who.int/topics/breastfeeding/en/

2. Betran AP, de Onvs M, Lauer JA, Villar J. Ecological study of effect of breast feeding on infant mortality in Latin America. BMJ 2001;323:303-6.

3. Jones G, Steketee RW, Black RE, Bhutta ZA, Morris SS., Bellagio Child Survival Study Group How many child deaths can we prevent this year. Lancet. 2003;362:65-71.

4. Ministry of Health and Family Welfare. National Family Health Survey (NFHS-3) National fact sheet India. Available at: http://www.nfhsindia.org/pdf/IN.pdf. 
5. Sinhababu Apurba et al; Infant and Young child feeding practices in Bankura district, West Bengal, India. J Health Popul Nutr. 2010 June; 28(3): 294-299.

6. Joshi S, Barkakoti B, Lamsal S. Colostrum Feeding: Knowledge, Attitude and Practice in Pregnant Women in a Teaching Hospital in Nepal . WebmedCentral:International Journal of Medicine and Molecular Medicine 2012;3(8):WMC003601

7. Oommen $A$ et a. Breast feeding practices of rural and urban mothers. Indian Pediatrics 2009;46: 891-894.

8. Bhosale NA, Deshpande SG, Zodpey SP, Jog SN, Vasudeo ND. Infant feeding practices in urban population--a clinic based study. Indian J Med Sci 1997;51:396-9. Available from: http://www.indianjmedsci.org/text.asp?1997/51/10/396/11487

9. Panwar, et al . "Measurement of Progress Towards Mid Decade Goals for Children at District Agra", MD (SPM) Thesis submitted to SN Medical College, Agra; 1997.

10. UNICEF and Department of Women and Child Development, Ministry of Health and Family Welfare; Multi Indicator Cluster Survey; 2000.

11. Borade A, Hanumante N. Maternal Knowledge and Perception about the Breast Feeding and Factors Influencing it - A Study in Urban Low Socioeconomic Class of Pune. Pediatric Oncall [serial online] 2007 [cited 2007 November 1];5.

12. R.K. Chudasama, P.C. Patel, A.B. Kavishwar; Breast feeding initiation practice and factors affecting breast feeding in South Gujrat region of India. The Internet Journal of family practice. 2009; 7(2). DOI: 10.5580/14b

Table 1: Data on knowledge and feeding practices of the study population.

\begin{tabular}{|l|l|l|l|}
\hline Sl No. & Feeding practices & Yes & No \\
\hline 1. & Whether EBF given or not & $80(59 \%)$ & $55(41 \%)$ \\
\hline 2. & Knowledge on colostrum & $74(55 \%)$ & $61(45 \%)$ \\
\hline 3. & Whether colostrums given or not & $\begin{array}{l}109 \\
(80.75 \%)\end{array}$ & $26(19.25 \%)$ \\
\hline 4. & Any pre lacteals given & $28(21.75 \%)$ & $107(78.25 \%)$ \\
\hline 5. & Whether feeding initiated within 1 hour & $42(31.11 \%)$ & $93(68.89 \%)$ \\
\hline 6. & Weaning at 6 months & $35(25.9 \%)$ & $100(74.07 \%)$ \\
\hline
\end{tabular}


Table 2: Table showing association of feeding practices with demographic variables:

\begin{tabular}{|c|c|c|c|c|c|}
\hline SL No & Variable & \multicolumn{2}{|c|}{ Feeding practices } & \multirow[t]{2}{*}{ Total } & \multirow{2}{*}{$\begin{array}{l}\text { Chi Sq } \\
\text { P value }\end{array}$} \\
\hline \multirow[t]{5}{*}{1.} & Mothers age & EBF given & EBF not given & & \\
\hline & $<25$ & $26(19.26 \%)$ & $14(10.37 \%)$ & $40(29.63 \%)$ & \multirow[t]{4}{*}{$\begin{array}{l}\text { Chi Sq=8.546, } \mathrm{df}=2 \text {, } \\
\mathrm{P}=0.0139 .\end{array}$} \\
\hline & $26-35$ & $49(36.29 \%)$ & $28(20.74 \%)$ & $77(57.04 \%)$ & \\
\hline & $36-45$ & $5(3.72 \%)$ & $13(9.62 \%)$ & $18(13.33 \%)$ & \\
\hline & Total & $80(59.27 \%)$ & $55(40.73 \%)$ & $135(100 \%)$ & \\
\hline \multirow[t]{4}{*}{2.} & Family type & EBF -Yes & EBF-No & Total & \multirow{4}{*}{$\begin{array}{l}\text { Chi Sq=12.244, } \mathrm{df}=1 \\
\mathrm{P}=0.0005,0 \mathrm{R}=0.2595 \\
95 \% \mathrm{CI}=0.1244-0.5416\end{array}$} \\
\hline & Nuclear & $31(23 \%)$ & $39(29 \%)$ & $70(52 \%)$ & \\
\hline & Joint & $49(36 \%)$ & $16(12 \%)$ & $65(48 \%)$ & \\
\hline & Total & $80(59 \%)$ & $55(41 \%)$ & $135(100 \%)$ & \\
\hline \multirow[t]{4}{*}{3.} & Mothers occupation & EBF given & EBF not given & Total & \multirow{4}{*}{$\begin{array}{l}\text { Chi Sq }=0.7852 \\
d f=1, p=0.3755 \\
\text { OR=1.753 } \\
95 \% \text { CI }=0.6612-4.648\end{array}$} \\
\hline & Not Working & $71(53 \%)$ & $45(33 \%)$ & $116(86 \%)$ & \\
\hline & Working & $9(7 \%)$ & $10(7 \%)$ & $19(14 \%)$ & \\
\hline & Total & $80(60 \%)$ & $55(40 \%)$ & $135(100 \%)$ & \\
\hline \multirow[t]{4}{*}{4.} & Mothers education & EBF given & EBF not given & Total & \multirow{4}{*}{$\begin{array}{l}\text { Chi Sq }=9.903, d f=1 \\
p=0.0016,0 R=3.611 \\
95 \% C I=1.667-7.821\end{array}$} \\
\hline & Literate & $65(48 \%)$ & $30(22 \%)$ & $95(70 \%)$ & \\
\hline & Illiterate & $15(11 \%)$ & $25(19 \%)$ & $40(30 \%)$ & \\
\hline & Total & $80(59 \%)$ & $55(41 \%)$ & $135(100 \%$ & \\
\hline \multirow[t]{4}{*}{5.} & Mothers education & $\begin{array}{l}\text { Knowledge on } \\
\text { colostrums- } \\
\text { Yes }\end{array}$ & $\begin{array}{l}\text { Knowledge on } \\
\text { colostrums-No }\end{array}$ & Total & \multirow[t]{4}{*}{$\begin{array}{l}\text { Chi } \mathrm{Sq}=25.855, \mathrm{df}=1 \text {, } \\
\mathrm{P}<0.0001,0 \mathrm{R}=9.103 \\
95 \% \mathrm{CI}=3.740-22.158 .\end{array}$} \\
\hline & Literate & $66(49 \%)$ & $29(21 \%)$ & $95(70 \%)$ & \\
\hline & Illiterate & $8(6 \%)$ & $32(24 \%)$ & $40(30 \%)$ & \\
\hline & Total & $74(55 \%)$ & $61(45 \%)$ & $135(100 \%)$ & \\
\hline \multirow[t]{4}{*}{6.} & Mothers education & $\begin{array}{l}\text { Colostrum } \\
\text { given }\end{array}$ & $\begin{array}{l}\text { Colostrum not } \\
\text { given }\end{array}$ & Total & \multirow{4}{*}{$\begin{array}{l}\text { Chi } \quad \mathrm{Sq}=31.791, \quad \mathrm{df}=1, \\
\mathrm{p}<0.0001, \\
\text { OR=14.833, } \\
95 \% \mathrm{CI}=5.277-41.684\end{array}$} \\
\hline & Literate & $89(65.92 \%)$ & $6(4.44 \%)$ & $95(70.37 \%)$ & \\
\hline & Illiterate & $20(14.83 \%)$ & $20(14.81 \%)$ & $40(29.63 \%)$ & \\
\hline & Total & $109(80.75 \%)$ & $26(19.25 \%)$ & $135(100 \%)$ & \\
\hline \multirow[t]{4}{*}{7.} & Place of delivery & $\begin{array}{l}\text { Initiated } \\
\text { within } 1 \text { hour }\end{array}$ & Initiated after $1 \mathrm{hr}$ & Total & \multirow{4}{*}{$\begin{array}{l}\text { Chi Sq=1.661, } \mathrm{df}=1, \\
\mathrm{P}=0.1974,0 \mathrm{R}=0.3702, \\
95 \% \mathrm{CI}=0.1017-1.348\end{array}$} \\
\hline & Home & $3(2.23 \%)$ & $16(11.85 \%)$ & $19(14.07 \%)$ & \\
\hline & Institutional & $39(28.88 \%)$ & $77(57.03 \%)$ & $116(85.93 \%)$ & \\
\hline & Total & $42(31.11 \%)$ & $93(68.89 \%)$ & $135(100 \%)$ & \\
\hline
\end{tabular}

